IP Periodica Polytechnica

Transportation Engineering

46(3), pp. 117-121, 2018

https://doi.org/10.3311/PPtr. 12127

Creative Commons Attribution (i)

RESEARCH ARTICLE

\section{Comparison of Self-reported and Observed Road Safety Performance Indicators}

\author{
Péter Holló $^{1 *}$, Diána Henézi ${ }^{2}$, Tamás Berta ${ }^{1}$
}

Received 18 January 2018; accepted 22 February 2018

\begin{abstract}
The first concept of road safety performance indicators was published by European Transport Safety Council, Brussels in 2001. Hungary has long and reliable time series of safety belt wearing and child safety seat usage rates in passenger cars. These rates are based on real roadside observations and representative sample, meeting the requirements of international road accident databases. The methodology of the data collection has been further developed during the recent years, but we paid attention to the possibility of comparison with the earlier data and consistent analysis of time series. Although the roadside observations could not have been organized in each year, the trends can be seen relatively well. Our initial hypothesis was that the self-reported data always show a bit "better" picture about the driving behaviour than the observed ones, since the people are not sure that their data will be handled in an anonym way. Based on these results we can say that the ESRA results are relatively good estimations of the real safety belt wearing rates.
\end{abstract}

\section{Keywords}

road safety, indicators, analysis

\footnotetext{
${ }^{1}$ Road Safety Centre, KTI - Institute for Transport Sciences Non Profit Ltd., H-1111, Budapest, Than Karoly str 3-5.

${ }^{2}$ Széchenyi István University

Győr, Egyetem tér 1., 9026

* Corresponding author, e-mail: hollo.peter@kti.hu
}

\section{Introduction}

The first concept of road safety performance indicators was published by ETSC (European Transport Safety Council, Brussels) in 2001 (ETSC, 2001). The detailed data requirements and theory of these indicators have been elaborated in the framework of the Safety Net EU project (Hakkert et al., 2007). Hungary has long and reliable time series of safety belt wearing and child safety seat usage rates in passenger cars (Fig. 1). (Holló et al., 2010; Holló and Berta, 2017). These rates are based on real roadside observations and representative sample, meeting the requirements of international road accident databases. As far as we know, only the database of OECD member countries, the International Road Traffic and Accident Database: IRTAD) consists of such indicators, differentiated by road categories and seat positions. Only daytime safety belt wearing rates can be found in the database, in accordance with the basic principles elaborated in Safety Net project (Hakkert et al., 2007).

It is important to take into account the uniform concepts and definitions, otherwise we will lose one of the major aims of the data collection: the international comparison. The methodology of the data collection has been further developed during the recent years, but we paid attention to the possibility of comparison with the earlier data and consistent analysis of time series. We differentiate not only the persons sitting in the front and back seats but the driver and front seat passenger too. Adults and children are differentiated also, so in our opinion the survey gives enough knowledge to the determination of the main points of the injury prevention and road safety information and campaigns.

In our opinion such kinds of observations are necessary, since they give a real picture about the whole motorist population. The indicators coming from the analysis of accident data can only valid for the people involved in accidents. We do not believe that these results could be representative for the whole motorist community. In our opinion the group of people involved in accidents cannot be representative for the whole motorist population. It seems more realistic that this group is a so-called "high risk" group. This statement is confirmed by a Norwegian research, according which "when we study severe road accidents, there is an over-representation of drivers who 


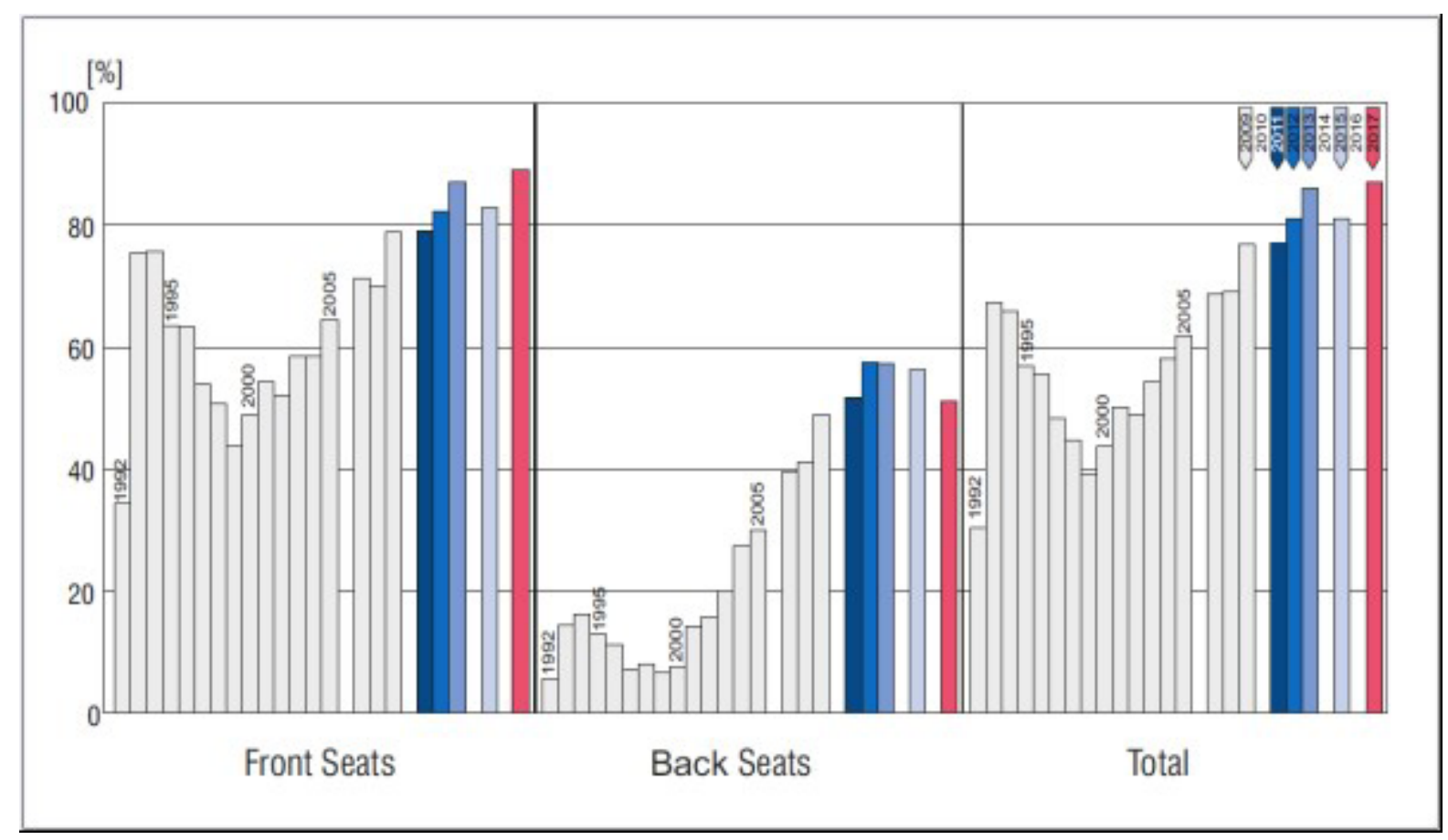

Fig. 1 Safety belt wearing rates in passenger cars in Hungary

drive too fast, do not use seat belts, or who drive under the influence of alcohol or other drugs." (Statens vegvesen, 2010; Tison et al., 2010). If the real road safety indicators could have been determined by analysis of road accident data, nobody would organize real roadside observations, it would be enough just to analyse the road accident data sitting behind a desk.

Of course, not only the safety belt wearing rates, but the child seat usage rates are available too. In the Fig. 2 we illustrate the development of child safety usage rates in Hungary.

Regarding the Fig. 2, we mention the most important dates in connection with development of the different rates. The most important milestones of the development are as follows:
- 01.01.2012: introduction of obligatory usage of child safety seats;

- 01.04.2007: change in legislation (introduction of simpler rules);

- 01.01.2008: further elaboration of demerit point system (it became stricter);

- 01.01.2009: general safety requirements became stricter (international legislation).

\section{Aim and methodology of research}

Although the roadside observations could not have been organized in each year, the trends can be seen relatively well.

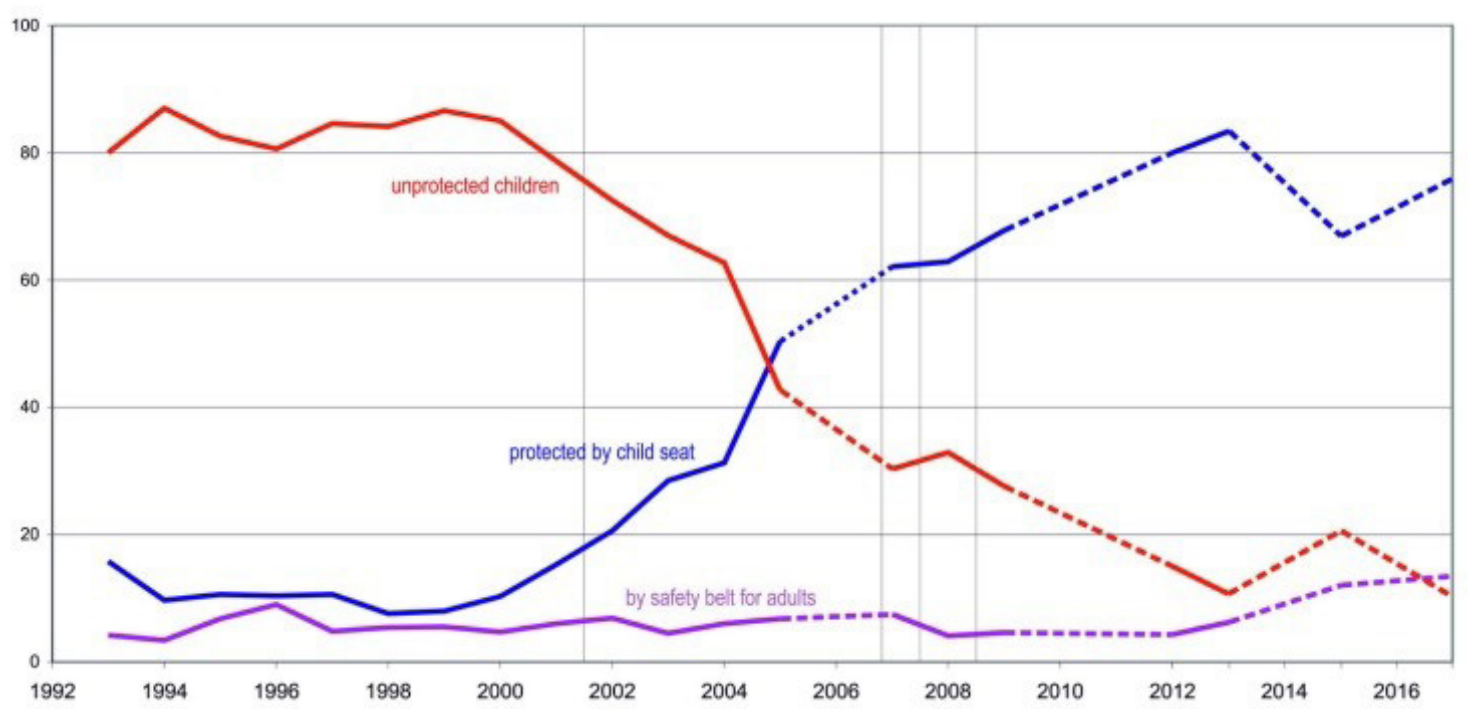

Fig. 2 Percentage of unprotected and protected children in passenger cars in Hungary between 1993 and 2017 
Due to the ESRA (first European Survey of Road Users' safety Attitudes, later: E-Survey of Road Users' Attitudes) project (ESRA, 2017), led by the Belgian VIAS Institute, some selfreported road safety performance indicators are available, too. The ESRA project is a joint initiative of research institutes in 25 countries aiming at collection of comparable national data on road users' opinions, attitudes, and self-reported behaviour with respect to road traffic risks. In total, ESRA gathered data from almost 27000 road users in 2015 and 2016. So it became possible to compare the results of the real world observations and the ESRA survey (self-reported data).

Our initial hypothesis was that the self-reported data always show a bit "better" picture about the driving behaviour than the observed ones, since the people are not sure that their data will be handled in an anonym way.

The comparison was complicated by the fact, that the time frames were different. The exact period of the data collection in the ESRA project was between 28/09 and 05/10 in 2016. The roadside observations were organized in 2013, 2015 and in 2017.

\section{Results}

The Fig. 3 illustrates the safety belt wearing rates of passenger car drivers according to the roadside observations (2013, 2015, and 2017) and to the ESRA project (2016). Fig. 4 shows the same for back seat passengers.

In case of car drivers, the confidence intervals are not disjunctive; this means that there is no significant difference between the self-reported and observed performance indicators. In case of back seat passengers, the confidence intervals are also not disjunctive. Since the overlap is very small, here the difference between the real world measurements and the questionnaire results is bigger, but not significant.

Based on these results we can say that the ESRA results are relatively good estimations of the real safety belt wearing rates, especially in the front seats of passenger cars.

It is also interesting to compare the Hungarian data with the European ESRA mean. The safety belt wearing rate of the Hungarian car drivers was $85.1 \%$ in the ESRA survey in 2016, higher than the European ESRA mean (80.3\%). The situation was the opposite in case of the back seats, where the Hungarian data was 55.2\%, lower than the European ESRA mean (62.2\%).

We compared the observed and self-reported child safety seat usage rates as well. The results can be seen in Fig. 5. Before the comparison, we can state based on the country fact sheet (ESRA, 2017) that the Hungarian child safety seat usage rate (in case of children under $150 \mathrm{~cm}$ height) was $83.2 \%$ in 2016 , significantly higher than the European ESRA mean (63.3\%).

In case of child seat usage rates the confidence intervals are not disjunctive, too; this means that there is no significant difference between the self-reported and observed performance indicators.

Regarding the restraint systems, a relatively good conformity can be stated between the self-reported and the observed data. The situation is more complicated in other areas of road safety performance indicators.

According to the ESRA project (ESRA, 2017) 39.2\% of the Hungarian drivers talk on a hand-held mobile phone while driving. (The ESRA mean is $38 \%$ here). Based on the results of real roadside observations the rate of such drivers was 5-6\%.

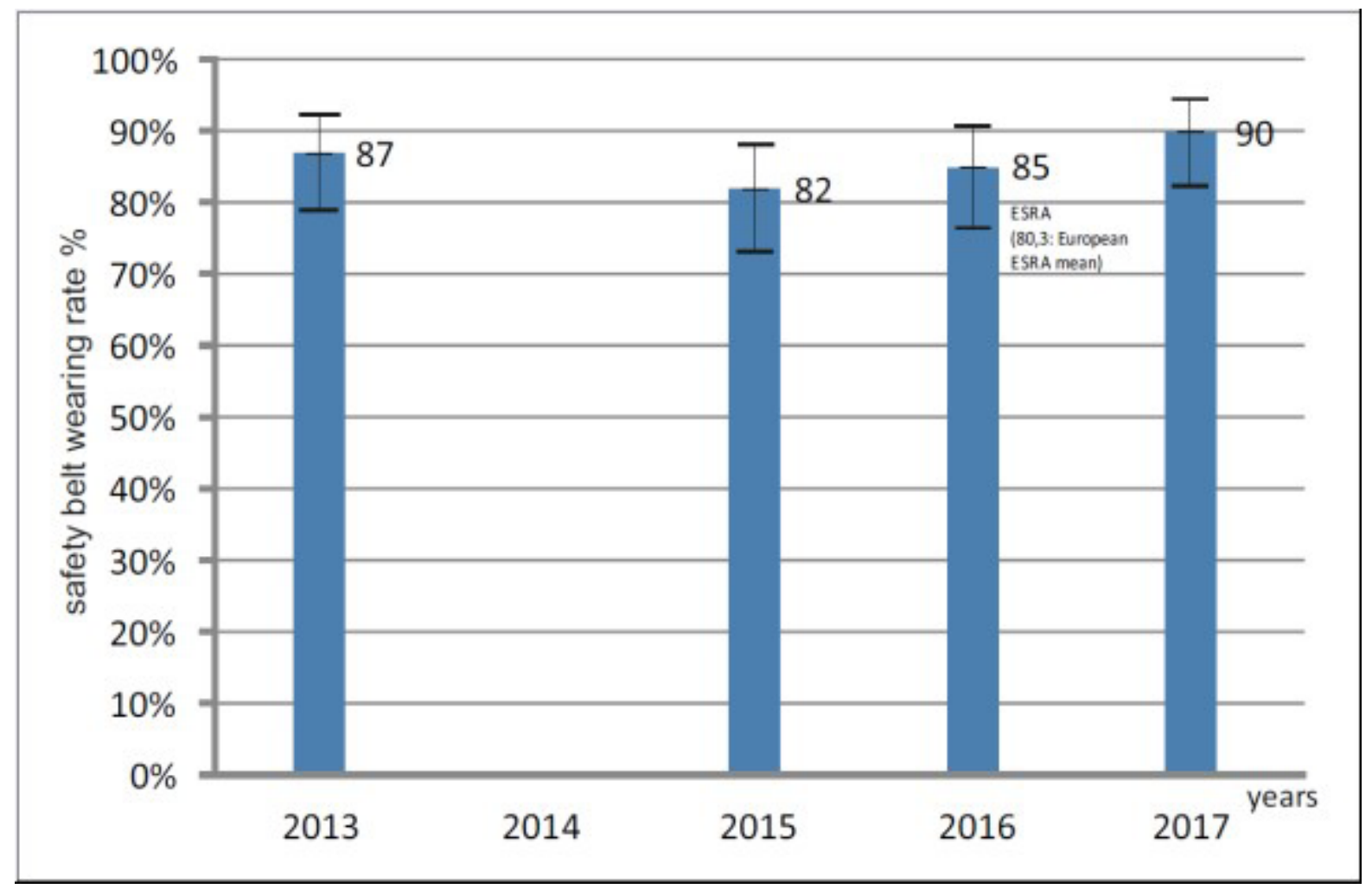

Fig. 3 Safety belt wearing rates of car drivers according to the roadside observations (2013, 2015, and 2017) and to ESRA results (2016). 


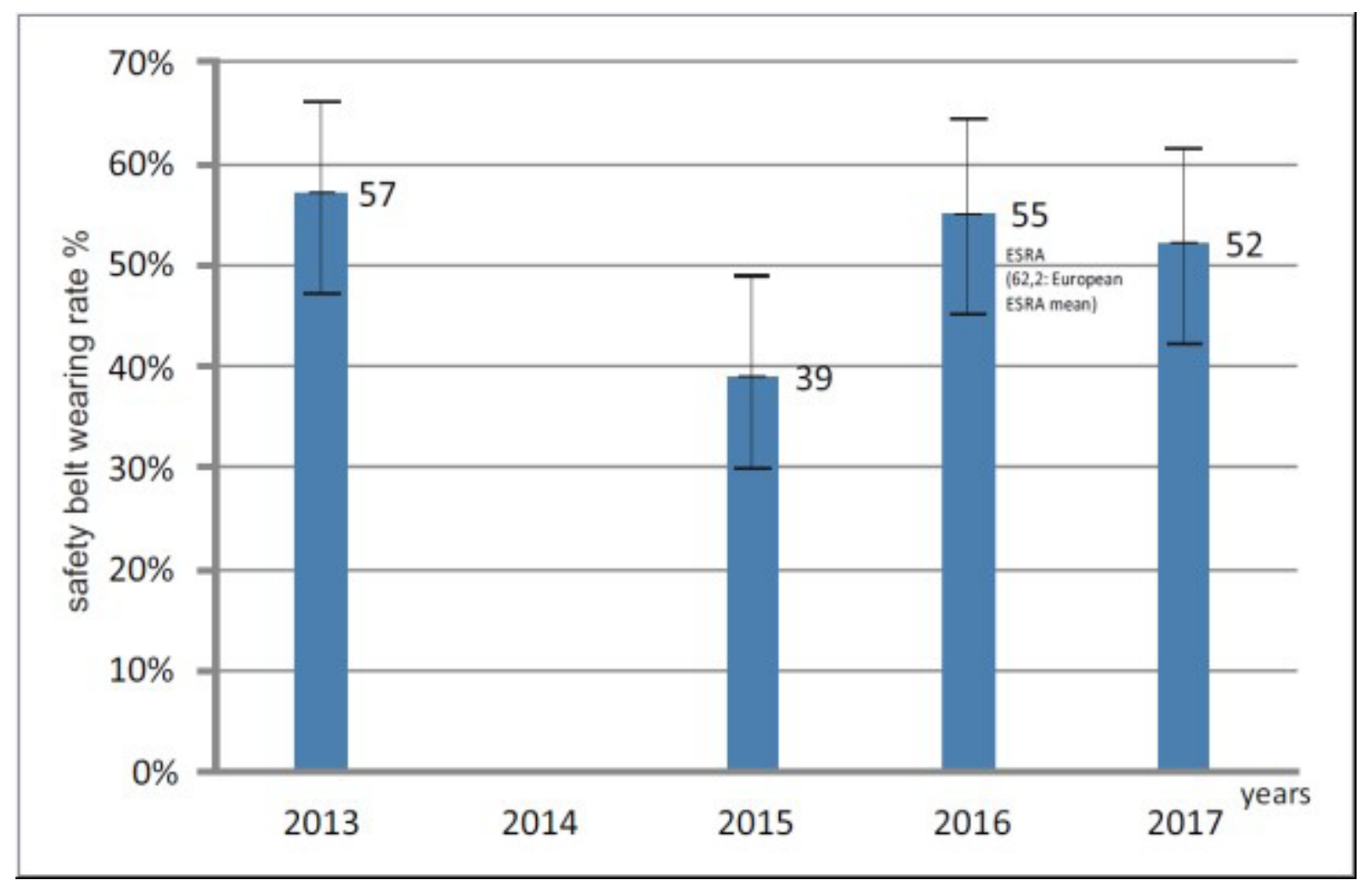

Fig. 4 Safety belt wearing rates of back seat car passengers according to the roadside observations (2013, 2015, and 2017) and to the ESRA results (2016).

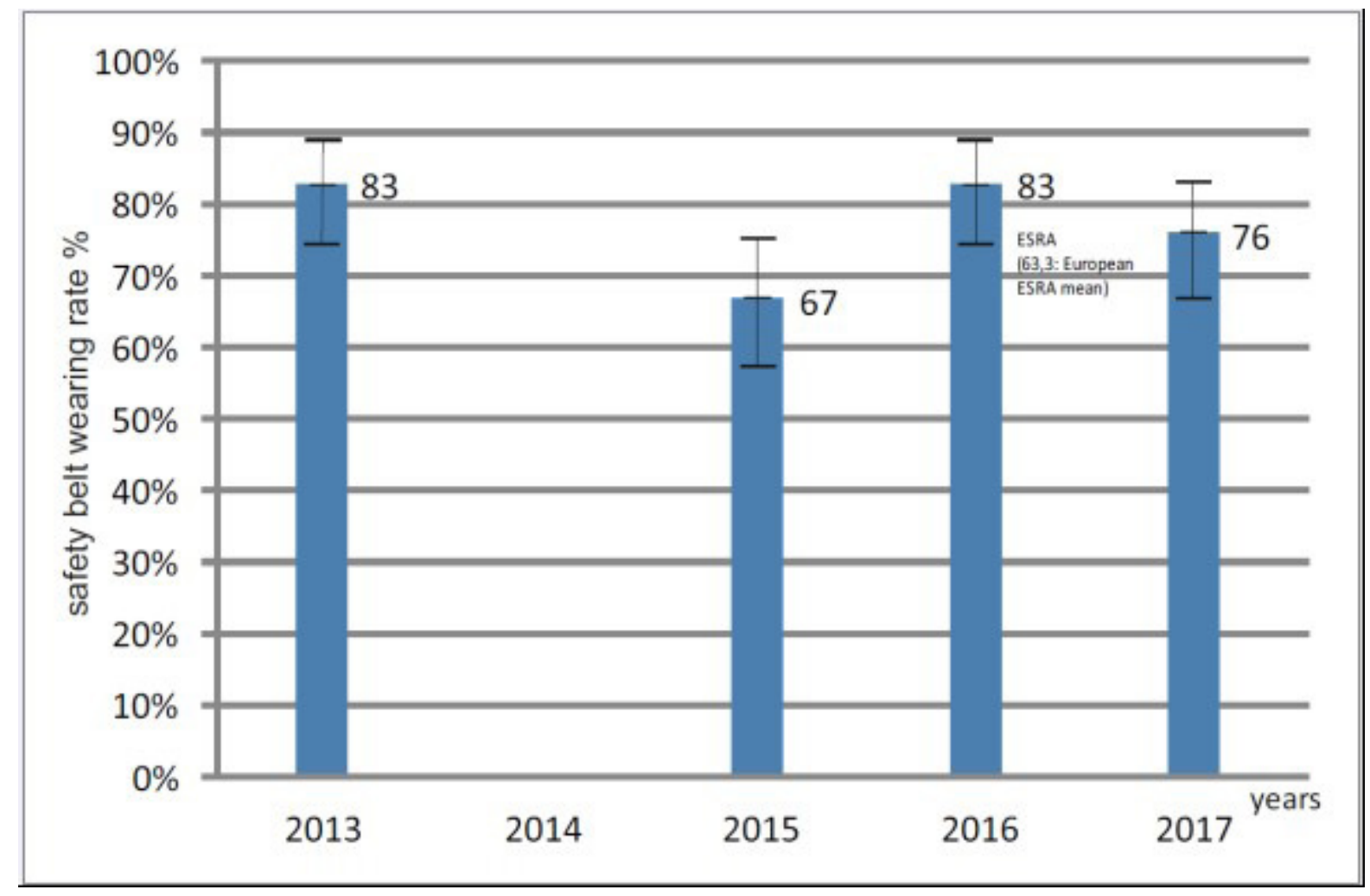

Fig. 5 Child seat usage rates according to the roadside observations (2013, 2015, and 2017) and to the ESRA results (2016).

Although there is a contradiction here at the first sight, we have to be careful during the interpretation of the difference. The roadside observation gives a snapshot of the situation, in other words: how many drivers use the mobile phone while driving in the period of the observation. The question of the ESRA project was in contradiction to this: "in the past 12 months, as a road user, how often did you talk on a hand-held mobile phone while driving?" The 39.2\% means that they used their mobile phone at least once in the past 12 months. 
We know that there is a great difference between the crash helmet usage rates of motorbike and moped riders. In case of motorbike riders, it is almost $100 \%$, especially in Budapest, whereas in case of moped riders it is lower. Both in the ESRA project and in our roadside observations these two categories of motorized two wheelers belong into one group, which makes the in-depth analysis and the identification of the main target group impossible. Therefore we suggest the separation of these categories.

\section{Conclusion}

Regarding the restraint systems, a relatively good conformity can be stated between the self-reported and observed data. It means that the self-reported data can be used as a relatively good estimation (proxy) of the real values in this field of road safety performance indicators. The comparison is not so easy in other areas of the road safety performance indicators. At the first sight there is a great difference for example between the hand-held mobile phone usage rates while driving. It has to be taken into account that the interpretation of the question is different here, which makes the direct comparison impossible.

In case of safety belt wearing rate of car drivers and child seat usage rates the Hungarian values are higher than the European ESRA mean, but in case of back seat car passengers they are lower. It means that the increase of the safety belt wearing rate of back seat car passengers is an important country specific task in Hungary.

\section{References}

ESRA project (E-Survey of Road Users' Attitudes) (2017). Country fact sheet Hungary 2016, Brussels, [pdf]. Available from: http://www.vias.be/en/ companies-and-government/projects/international/esra/ [Accessed: 9th February 2018]

European Transport Safety Council (2001). Transport Safety Performance Indicators, Brussels,

Hakkert, A. S, Gitelman, V., Vis, M. A. (eds.) (2007). Road Safety Performance Indicators: Theory. Deliverable D3.6 of the EU FP6 project SafetyNet.

Hollo, P., Berta, T., (2017). Comparison of self-reported and observed road safety performance indicators. In Poster at 6th IRTAD Conference - Better Road Safety Data for Better Safety Outcomes. Marrakech, Oct. 10-12, 2017.

Holló, P., Eksler, V., Zukowska, J. (2010). Road safety performance indicators and their explanatory value: A critical view based on the experience of Central European countries. Safety Science. 48(9), pp. 1142-1150. https://doi.org/10.1016/j.ssci.2010.03.002

Statens vegvesen (2010). High Risk Groups in Road Traffic, Oslo, Norway, [online] Available from: https://www.vegvesen.no/en/professional/ research+and+development/High+Risk+Groups+in+Road+Traffic [Accassed: 9th February 2018]

Tison, J., Williams, A. F., Chaudhary, N. K. (2010). Daytime and Nighttime Seat Belt Use by Fatally Injured Passenger Vehicle Occupants, National Highway Traffic Safety Administration, U.S. Department of Transportation 